\title{
80 anos do Serviço Social no Brasil: a certeza na frente, a história na mão*
}

\section{0 years of Social Work in Brazil: certainty ahead, history in hand}

\author{
Marilda Villela lamamoto \\ Universidade do Estado do Rio de Janeiro/Faculdade de Serviço Social; pesquisadora do Conselho \\ Nacional de Desenvolvimento Científico e Tecnológico/Rio de Janeiro/RJ, Brasil.
}

mviamamoto@uol.com.br

\begin{abstract}
Resumo: O texto versa sobre o tema central do XV Congresso Brasileiro de Assistentes Sociais, realizado em setembro de 2016, em Pernambuco. Contextualiza o Serviço Social em tempos de crise econômica e política no país, com ampla investida contra o legado de direitos dos trabalhadores e avanço na privatização da coisa pública, salientando distintas formas de resistência de segmentos organizados de trabalhadores contra as desigualdades e disparidades sociais. Apresenta um quadro da situação atual do trabalho e formação acadêmica no Serviço Social brasileiro e efetua uma retrospectiva dessas oito décadas de seu desenvolvimento e renovação crítica. Registra alguns desafios ao Serviço Social em tempos de crise e conclui afirmando a necessidade de qualificar o exercício profissional, de retomar o trabalho de educação de base no apoio à organização e aos movimentos dos trabalhadores na defesa dos direitos conquistados e da democracia.
\end{abstract}

Palavras-chave: História do Serviço Social no Brasil. Fundamentos do Serviço Social. Trabalho profissional.
Abstract: The text is related to the central issue of the $\mathrm{XV}^{\text {th }}$ Brazilian Social Workers' Congress, which took place in Pernambuco, in September 2016. It contextualizes the social work in times of economic and political crisis in the country, times in which there has been a wide assault on the legacy of workers' rights and advances in the privatization of public property. It is stressed the different forms of resistance against social inequalities and disparities by organized segments of workers. The article presents a frame of the current situation of the work and the academic education of the Brazilian Social Work, and it looks back on these eight decades of its development and critical renewal. It lists some challenges to Social Work in times of crisis, and it finishes by stating the need to qualify the professional practice, and to resume basic education work to support the workers' organization and movements to defend the rights gotten and democracy.

Keywords: History of the Brazilian Social Work. Social Work fundamentals. Professional practice.

* Este é o texto base da conferência de abertura do XV Congresso Brasileiro de Assistentes Sociais realizado em Olinda (PE), no período de 5 a 9 de setembro de 2016, versando sobre o tema central do evento. A mesa de abertura foi partilhada com a prof. Ana Elizabeth Mota, sob a coordenação das colegas Adiliane Batista (Cress- $4^{a}$ Região) e Joseane Soares (CFESS). Reafirmo meus agradecimentos ao Conselho Regional 


\section{Introdução}

$\mathrm{N}$

o atual momento da história política brasileira, a chamada do XV Congresso Brasileiro de Assistentes Sociais (CBAS) se encorpa de força política. "Com a certeza na frente e a história na mão" somos chamados a resistir, a defender a democracia, os direitos sociais conquistados e sua ampliação, a política pública, em particular a seguridade social estatal, ampliada e universal. E fortalecer as formas de organização dos trabalhadores para fazer valer nossa voz — com a voz de muitos brasileiros —, repudiando o golpe político-institucional contra a democracia, na defesa dos direitos conquistados e pela sua ampliação.

Este CBAS ocorre em tempos intempestivos e "temerários" — como sugere o CFESS — , que são também tempos de organização e de luta: "quem sabe faz a hora, não espera acontecer". Repudiamos o golpe contra a democracia desfechado pelas elites econômico-políticas no controle dos poderes do Estado, com o apoio da grande mídia, consubstanciado no impedimento da presidenta Dilma Rousseff. Ele foi orquestrado em sintonia com uma geopolítica dos centros mundiais de poder contra os governos progressistas de nuestra América como parte das estratégias anticíclicas apoiadas na exploração abusiva dos trabalhadores e de riquezas das regiões periféricas.

Sob o ângulo profissional, este CBAS é motivo de rememorar e comemorar: 80 anos da criação do primeiro curso de Serviço Social no Brasil, na atual PUC-SP; nove décadas de presença do Serviço Social na América Latina, completadas no ano passado, com o primeiro curso criado, em 1925, no Chile; 20 anos das diretrizes curriculares norteadoras da formação acadêmico-profissional, peça decisiva na constituição do projeto do Serviço Social brasileiro; 70 anos da Abepss e da Associación Latinoamericana de Enseñanza y Investigación en Trabajo Social (Alaeits); cinco décadas do movimento de reconceituação do Serviço Social latino-americano, que busca inscrever a profissão na história de nuestra América, com especial atenção às lutas, organizações

de Serviço Social - 4 ${ }^{\mathrm{a}}$ Região (Cress), ao Conselho Federal de Serviço Social (CFESS), à Associação Brasileira de Ensino e Pesquisa em Serviço Social (Abepss) e à Executiva Nacional de Estudantes de Serviço Social (Enesso) pela honra do convite. 
e movimentos das classes subalternas. É essa ambientação político-profissional que vai eclodir no Brasil, no CBAS de 1979, conhecido como Congresso da Virada ainda no bojo da crise da ditadura.

Ao lançar os olhos sobre tais comemorações, uma constatação se impõe: o Serviço Social latino-americano tem mais tempo em sua aproximação do pensamento histórico-crítico do que a prevalência exclusiva do pensamento liberal/conservador. Temos mais tempo de luta do que de exclusiva conivência com os centros de poder. Afirmam-se afinidades eletivas entre o Serviço Social e as necessidades, interesses e iniciativas politicas de distintos segmentos das classes subalternas e, em especial, os trabalhadores. Concorrem para esse aggiornamiento tanto os avanços na organização das forças contra-hegemônicas ao ordenamento instituído quanto a reserva de forças políticas, profissionais e de iniciativas internas à categoria de assistentes sociais.

Essa história nos orgulha como brasileiros e enche nossa alma de alegria. Sobre ela nos debruçamos nesta palestra salientando os desafios profissionais contemporâneos nesses tempos nebulosos, que desfiam a todos.

\section{Serviço Social em tempos de crise}

Nesses tempos de aridez de projetos de futuro, nos moldes da "grande política" e com base na economia política do trabalho, afirmamos a radical aposta humana na construção da história. Como já dizia um filósofo alemão: "Ser radical é tomar as coisas pela raiz. Mas a raiz, para o homem, é o próprio homem" (Marx, 1977, p. 8).

O presente retrocesso político-institucional ocorre no lastro da crise financeira desencadeada na Europa em 2007. Impulsionada pela falência do Banco Lehman em 2008, espraia-se na zona do euro e no circuito mundial. Na atualidade, como nos indica Chesnais (2001, 2013), o substrato da crise reside na superacumulação de capacidades de produção especialmente elevadas e na superprodução, acompanhadas de uma acumulação de capital fictício sem precedentes. Ela se sustenta na superexploração dos trabalhadores e na face desumana das guerras impulsionadas pelos núcleos de poder mundial. Reativa-se a intolerância política e religiosa, os xenofobismos, os deslocamentos 
forçados de massas de população em busca de um lugar para sobreviver assim como a resistência aos imigrantes e aos refugiados políticos.

Ao mesmo tempo, expande-se a pilhagem de recursos naturais do planeta e a crescente mercantilização das riquezas naturais: a exploração em molde capitalista de minerais, da água, do ar e das florestas, o que requer acesso à propriedade privada da terra e aos licenciamentos de parte do Estado para exploração econômica de recursos em regiões protegidas.

As políticas anticrise de raiz liberal são partes de um projeto de classe destinadas a restaurar e consolidar o poder do capital, privatizando lucros e socializando custos, como alerta Harvey (2011). Alarga-se a distância entre ricos e pobres, radicalizando as desigualdades sociais e as lutas contra as mesmas, o que se refrata no cotidiano de contingentes majoritários das classes subalternas.

No caso brasileiro, a crise econômica convive com a prolongada crise política no país. Amplia-se o espaço para o radicalismo de direita, a investida contra o legado de direitos dos trabalhadores e o avanço exponencial e veloz na privatização da coisa pública, ainda durante a interinidade de Michel Temer na presidência da República.

São exemplos: a extinção das secretarias especiais vinculadas com direitos — dos direitos humanos, das mulheres e da igualdade racial —; a extinção do Ministério do Desenvolvimento Agrário (MDA) e do Ministério do Desenvolvimento Social - MDS (MP n. 720 de 12/5/2016); a transferência para o Ministério da Fazenda da estrutura do Ministério da Previdência Social: o deslocamento do Instituto Nacional do Seguro Social (INSS) para o recém-criado Ministério do Desenvolvimento Social e Agrário (MP n. 726) (CFESS, 2016).

A proposta da desvinculação dos Recursos da União (DRU) foi prorrogada até 2023 (PEC n. 31/2016) e o valor das receitas foi ampliado para 30\%, extensiva aos estados e municípios em favor do ajuste fiscal e contra os direitos. Esse é um valor superior ao montante do orçamento destinado a assistência e política nacional de saúde, como registra o CFESS (2016).

A proposta de reforma da Previdência é presidida pela penalização dos trabalhadores com o aumento do valor de suas contribuições, a desindexação dos valores dos benefícios do salário mínimo, contribuição direta dos trabalhadores rurais, a unificação do regime da Previdência com o regime jurídico 
único, mudanças nas regras de aposentadoria. Tem-se, ainda, a proposta de limitação do gasto público por vinte anos com irreversíveis consequências na efetivação de direitos constitucionais, como consta da PEC de 24 de junho. Aliam-se indicativos de privatização do SUS e da universidade pública.

De outro lado, as relações sociais no campo são tensionadas pela liberação de venda de terras aos estrangeiros com derivações na demarcação das terras indígenas e das populações tradicionais; e a expropriação de recursos minerais, como, por exemplo, a privatização do Pré-Sal na exploração petrolífera.

Ao largo da grave crise político-institucional no país, são atualizados e radicalizados traços históricos persistentes de nossa burguesia associada e dócil à dependência externa, na condição de sócio menor dessa aliança. Ela apresenta especial devoção ao mandonismo local discricionário, alimentado pela apropriação privada da coisa pública mediante a captura do Estado nacional para seus fins privados. Esse é um reiterado traço da revolução burguesa no Brasil segundo interpretação de Florestan Fernandes (1976). Essa ocorre mantendo a dependência externa e a desigualdade do desenvolvimento interno, conduzido por uma burguesia nacional associada ao grande capital internacional. Aliam-se particularidades do liberalismo no Brasil: forjado no seio da escravatura saúda o ideário da Revolução Francesa nas suas atividades econômicas externas (Viotti da Costa, 1977). Em outros termos, a liberdade de mercado convive com o arbítrio e a força nas relações internas: o escravismo e o mandonismo local, (Iamamoto, 2001) que derivou nas várias expressões dos coronelismos na política regional. Esses traços persistentes se atualizam, sob inéditas condições históricas, na recente tragédia da política brasileira, como todos pudemos testemunhar na Câmara dos Deputados e no Senado Federal quando da votação de impedimento da presidenta da República.

No campo da resistência, as forças de esquerda sofrem importantes impactos em decorrência dos efeitos da crise no trabalho, no emprego e na sua força política. Tem-se o descenso na luta dos trabalhadores, a intensificação da repressão e a criminalização das formas de resistência. Na última década, parcelas importantes dessas forças foram alvo de ampla investida governamental na cooptação e institucionalização de movimentos sociais que passam a depender do fundo público para o desenvolvimento de suas formas de organização e ação política em detrimento de sua autonomia de classe. 
Mas existe em nossa sociedade um terreno minado de resistências e lutas travadas no dia a dia de uma conjuntura adversa para as maiorias, lutas essas que carecem de maior organicidade para terem força na cena pública. Além das greves de trabalhadores cujas ocorrências já superam as das década de 1980 e 1990, podem ser lembradas: as lutas dos "trabalhadores sem-terra" pela reforma agrária; o movimento das nações indígenas pela preservação de seu patrimônio material e cultural; as lutas das mulheres contra a opressão, pela legalização do aborto e pelo reconhecimento de seus direitos; dos velhos trabalhadores, hoje aposentados, pela preservação dos direitos conquistados na Previdência Social; dos afrodescendentes, pela preservação de suas raízes e direitos; dos migrantes que atravessam as fronteiras nacionais, na defesa de sua cultura e de sua integração na nova sociedade; dos estudantes secundaristas, na defesa da educação por meio da ocupação das escolas; da juventude trabalhadora da periferia das grandes cidades, na defesa de suas expressões culturais e contra o genocídio de jovens, negros, pobres das periferias urbanas, a luta contra a fobia LGBT. Essa multiplicidade de sujeitos e de formas de luta tem uma trama comum, oculta na diversidade de suas expressões: a dos despossuídos de propriedade para produzir seus meios de vida numa sociedade de desiguais.

Diante desse quadro, é necessário contribuir na construção de um projeto para o Brasil — parafraseando Celso Furtado (1967) — que seja a gravitação política de uma grande frente de esquerda, enraizado numa clara dimensão de classe, fundado no universo do trabalho e das maiorias trabalhadoras; e que contemple a questão nacional e a democratização do Estado.

O Serviço Social brasileiro assumiu um ideário emancipatório, herdeiro da história da luta mundial dos trabalhadores, calcada na grande política e em valores que dignificam o gênero humano. O nosso projeto está fundado nos valores maiores da liberdade, da igualdade, da radicalidade democrática, da cidadania, da ausência de preconceitos, do respeito aos direitos humanos, da qualidade dos serviços prestados. Ele representa o antídoto para enfrentar a alienação do trabalho indissociável do estatuto do assalariado. Dotado de "caráter ético-político", dispõe de uma dimensão de universalidade impregnando o trabalho cotidiano de interesses da coletividade ou, em termos gramscianos, da "grande política", como momento de afirmação da teleologia e da liberdade na práxis social (Coutinho, 1989). 
Esse projeto preserva sua autonomia ante os partidos e as forças de esquerda, não podendo ser subsumido aos destinos do Partido dos Trabalhadores nem de nenhum outro partido. Nosso projeto profissional nos dá mirada e norte. Ele nos desafia a decifrar a história e acumular forças políticas e competência profissional para sua viabilização com a certeza na frente e a história na mão. Esse projeto vê-se hoje tensionado por projetos societários conservadores, antiliberais e anticapitalistas de diversas matizes. $\mathrm{Na}$ atualidade, defronta-se com a forte ofensiva das forças regressivas travestidas nas instituições religiosas, no braço repressivo do Estado, nas organizações corporativas de várias frações da burguesia industrial e agrária e das camadas médias em luta pela hegemonia, na grande mídia, entre outros aparelhos de hegemonia que não podem ser subestimadas. A elas não é imune a categoria profissional.

$\mathrm{Na}$ disputa teórico-política de projetos contra-hegemônicos para o país - construídos de baixo para cima - estão envolvidos partidos e forças de esquerda e movimentos sociais. A eles unimos nossas forças: a de nossa organização profissional, a de nossa produção acadêmica e a do trabalho profissional em suas dimensões materiais e educativas.

Atribuir densidade ao processo de construção histórica dos valores emancipatórios em tempos de radicalização conservadora e de barbárie requer pensar estratégias cravadas no processo histórico brasileiro contemporâneo. Requer uma profissão inscrita no Brasil, bem como a construção coletiva de estratégias assentadas em um projeto para o Brasil, que permita às forças de esquerda dialogar e construir alianças e frentes de trabalho conjuntas, para além das palavras de ordem consensuadas. Emerge daí um grande desafio de todos nós: decifrar o enigma chamado Brasil de hoje: as classes e seus segmentos, as desigualdades, o Estado e as relações de poder e riqueza de suas expressões culturais.

\section{Quadro atual do Serviço Social na divisão do trabalho}

O quadro atual da profissão após 80 anos de existência pode ser assim sintetizado:

a) O contingente de assistentes sociais brasileiros é o segundo no cenário mundial, com 160 mil profissionais ativos, conforme dados do Conselho Federal 
de Serviço Social (CFESS), apenas superado pelos Estados Unidos. Na América Latina, a International Federation of Social Workers (IFSW) estima um total de 200 mil profissionais congregados em onze associações nacionais. $\mathrm{Na}$ Europa, são 170 mil assistentes sociais em 35 países. ${ }^{1}$

b) Temos uma sólida organização acadêmica e profissional, com entidades politicamente fortes, representativas e articuladas entre si, abrangendo todo o território nacional: Conselho Federal e 26 conselhos regionais de Serviço Social (CFESS-Cress), órgão responsável pela normatização e fiscalização do exercício profissional; Associação Brasileira de Ensino e Pesquisa em Serviço Social (Abepss), organismo político-acadêmico e associação científica que integra a formação nos níveis de graduação e pós-graduação, tendo a pesquisa e a produção acadêmica como eixos articuladores do desenvolvimento científico do Serviço Social; Executiva Nacional de Estudantes de Serviço Social (Enesso). Nas últimas décadas foram expandidas as relações internacionais, estimulando a organização do Serviço Social latino-americano e mundial.

c) A Lei n. 2.317/2010 reconhece a condição de trabalhador assalariado do assistente social e normatiza uma carga semanal de trinta horas de trabalho sem redução do salário, fruto de ampla mobilização da categoria. Hoje ela requer a defesa de sua implementação.

d) Os(as) assistentes sociais vêm construindo uma nova imagem social da profissão relacionada aos direitos, apoiando a participação qualificada dos sujeitos sociais em defesa de suas necessidades e direitos.

e) A formação em Serviço Social é de nível superior desde suas origens, sendo que a partir da década de 1970 foi inscrita no circuito universitário. Dispõe de diretrizes curriculares nacionais para o ensino de graduação propostas por nossas entidades representativas (Abess/Cedepss, 1996), aprovadas e reguladas pelo Estado. ${ }^{2}$ Elas norteiam os 567 cursos de graduação autorizados em agosto de 2012, 518 dos quais são privados $(91,4 \%)$ e 49, públicos (8,6\%). Os 230 cursos à distância são exclusivamente privados e correspondem a 44,4\%

1. Disponível em: $<$ http://ifsw.org/membership/>. Acesso em: 25 ago. 2016.

2. MEC-Sesu/Coness/1999. Disponível em: <http//portal.mec.gov.br >. Acesso em: 24 jul. 2014. 
do conjunto dos cursos privados, enquanto os presenciais somam 288, ou seja, $55,6 \%$ dos cursos privados. ${ }^{3}$

f) A pós-graduação stricto sensu na área de Serviço Social encontra-se consolidada com 52 cursos de pós-graduação em 2016, sendo 34 de mestrado e dezoito de doutorado, todos de caráter acadêmico, com ênfase em Serviço Social, políticas públicas e políticas sociais, segundo dados da Fundação Coordenação de Aperfeiçoamento do Ensino Superior (Capes). Não existem mestrados profissionais reconhecidos. Aliam-se cursos de especialização de nível de pós-graduação lato sensu. ${ }^{4}$

g) O Serviço Social é reconhecido como área de conhecimento no âmbito das Ciências Sociais Aplicadas pelas agências públicas oficiais de fomento à pesquisa e inovação tecnológica, conquista pioneira no Serviço Social latino-americano.

h) A maturidade de significativo contingente de pesquisadores na área de Serviço Social - com rica interlocução junto às Ciências Sociais e Humanas — adensa o mercado editorial especializado. O Serviço Social agrega à condição de profissão a dimensão de disciplina científica — uma importante conquista -, como vem salientando Mota (2016) —, afirmando o estatuto teórico da profissão e sua contribuição à produção de uma massa de conhecimento crítico na formação de cultura contra-hegemônica.

\section{0 Serviço Social e a reprodução das relações sociais}

O pressuposto da análise é que a história da sociedade é o terreno privilegiado para apreender as particularidades do Serviço Social: seu modo de atuar e de pensar incorporados ao longo de seu desenvolvimento. Sendo um produto sócio-histórico, a profissão adquire sentido e inteligibilidade na dinâmica societária da qual é parte e expressão. Nesse sentido, decifrar essa especialização

3. Dados de acordo com as Sinopses Estatísticas do MEC, totalizadas por Dahmer Pereira. Apud Iamamoto, 2014.

4. Disponível em: $<$ https://sucupira.capes.gov.br/sucupira/public/consultas/coleta/programa/quantitativos/quantitativoAreaAvaliacao.jsf $>$. Acesso em: 25 maio 2016. 
do trabalho supõe elucidar os processos sociais que geram a sua necessidade social, o significado de suas ações no campo das relações de poder econômico e político — das relações entre as classes e destas com o Estado —, assim como o envolvimento no debate teórico e cultural de seu tempo. Estabelece-se, pois, como quesito fundamental a indissociável articulação entre conhecimento $e$ história, entre teoria e realidade (prática social).

Desde a década de 1980 vimos salientando que o Serviço Social é uma especialização do trabalho da sociedade, inscrita na divisão sociotécnica do trabalho social, o que supõe afirmar o primado do trabalho na constituição dos indivíduos sociais. Ao indagar-se sobre o significado social do Serviço Social no processo de produção e reprodução das relações sociais, ${ }^{5}$ tem-se um ponto de partida e um norte. Este não é a prioridade do mercado, tão cara aos liberais. Para eles, a esfera privilegiada na compreensão da vida social é a da distribuição da riqueza, visto que as leis históricas que regem a sua produção são tidas como assemelhadas àquelas da natureza, de difícil alteração por parte da ação humana.

O exercício profissional é necessariamente polarizado pela trama de suas relações e interesses sociais. Participa tanto dos mecanismos de exploração e dominação quanto, ao mesmo tempo e pela mesma atividade, da resposta às necessidades de sobrevivência das classes trabalhadoras e da reprodução do antagonismo dos interesses sociais. Como a sociedade é atravessada por projetos sociais distintos — projeto de classes para a sociedade - tem-se um terreno sócio-histórico aberto à construção de projetos profissionais também diversos, indissociáveis dos projetos mais amplos para a sociedade. É essa presença de forças sociais e políticas reais que permite à categoria profissional estabelecer estratégias político-profissionais no sentido de reforçar interesses das classes subalternas, alvo prioritário das ações profissionais.

5. Lembremos que a reprodução das relações sociais na sociedade capitalista, a partir da teoria social crítica, é entendida como reprodução desta sociedade em sua totalidade, em seu movimento e em suas contradições: produção e reprodução de um modo de vida que envolve o cotidiano da vida social. Inclui os sujeitos e suas lutas sociais, as relações de poder e os antagonismos de classes. Abrange a reprodução da vida material e da vida espiritual, isto é, das formas de consciência social — jurídicas, religiosas, artísticas, filosóficas e científicas - , através das quais os homens tomam consciência das mudanças ocorridas nas condições materiais de produção da vida material, pensam e se posicionam na sociedade. 
Os assistentes sociais realizam, assim, uma ação de cunho socioeducativo na prestação de serviços sociais, viabilizando o acesso aos direitos e aos meios de exercê-los, contribuindo para que necessidades e interesses dos sujeitos sociais adquiram visibilidade na cena pública e possam ser reconhecidos, estimulando a organização dos diferentes segmentos dos trabalhadores na defesa e na ampliação dos seus direitos.

\section{Breve retrospectiva sobre o desenvolvimento e a renovação crítica do Serviço Social no Brasil}

Na década de 1930, o Serviço Social surge no Brasil intimamente vinculado às iniciativas da Igreja Católica, parte das estratégias de qualificação do laicato, especialmente sua parcela feminina - por meio dos movimentos da ação social e da ação católica —, em sua missão de apostolado junto à família operária. Registram-se, nas origens da profissão, fortes influências do Serviço Social francês e belga.

O período de 1936 a 1945 marca o surgimento das primeiras escolas de Serviço Social e sua expansão no país, com prevalência da influência católica. Em 1936 é criado o primeiro curso na Escola de Serviço Social de São Paulo (que se incorpora à PUC-SP em 1972). ${ }^{6}$ A influência católica prevalecente nas origens tem sido foco da maior parte das pesquisas da área (Iamamoto e Carvalho, 1982; Yazbek, 1980). De menor investimento na pesquisa são as iniciativas do Estado na formação profissional, seja em aliança com a Igreja, seja sob influência do movimento sanitarista. E ainda as iniciativas partícipes do movimento da Escola Nova, marco inaugural do projeto de renovação educacional do país. ${ }^{7}$

6. Ela é seguida, em 1937, da Escola de Serviço Social do Instituto de Educação Familiar e Social, no Rio de Janeiro, agregada à PUC-RJ, em 1946. Em 1940, surge o Instituto de Serviço Social de São Paulo e no mesmo ano tem origem a Escola de Serviço Social de Pernambuco, a primeira do Nordeste, incorporada à UFPE em 1970. Ainda na região, em 1944, é fundada a Escola de Serviço Social da Bahia (integrando-se à Universidade Católica de Salvador em 1961). A Escola de Serviço Social do Paraná é criada em 1945, (integrada à Pontifícia Universidade Católica do Paraná em 1969) e a Escola de Serviço Social de Porto Alegre, em 1945 (integrada à Universidade Católica em 1948).

7. De iniciativa do Estado, são registradas as seguintes escolas no período: 1937: Centro de Serviço Social da Escola de Enfermagem Ana Nery, na Universidade do Brasil, atual UFRJ; 1940: Escola de Serviço 
A Sociedade Brasileira de Higiene, fundada em 1923, abria o caminho ao Serviço Social na perspectiva de uma ação essencialmente educativa individual e coletiva no âmbito da saúde pública, visando a prevenção de doenças de massa, nas trilhas de Oswaldo Cruz, Carlos Chagas e outros. Em 1930 é criado o Ministério da Educação e Saúde e, mais tarde, o Serviço Especial de Saúde Pública.

A Escola Nova defendia a bandeira de uma escola única, pública, laica, obrigatória e gratuita, alvo de forte e continuada crítica da Igreja Católica, concorrente do Estado na educação da população, que tinha sob seu controle a orientação de parcela expressiva das escolas da rede privada. O caso mais exemplar é o da Escola Técnica Cecy Dodsworth, atual Faculdade de Serviço Social da Uerj. Sua fundadora, Isolina Pinheiro (Pinheiro, 1985a, 1985b), defendia a Escola Nova, cujos princípios foram proclamados no Manifesto dos Pioneiros da Escola Nova, lançado em 1932. Redigido por Fernando de Azevedo, o texto foi assinado por 26 grandes intelectuais da época, entre os quais Anísio Teixeira, Afrânio Peixoto, Lourenço Filho, Roquette Pinto, Delgado de Carvalho e Cecília Meireles.

O Serviço Social desenvolve-se após a Segunda Guerra Mundial nos chamados "trinta anos gloriosos", que marcaram uma ampla expansão da economia capitalista. Sob a hegemonia do capital industrial, inspirada no padrão fordista-taylorista, a produção em massa para o consumo de massa dinamiza a acumulação de capital, gerando excedentes. Parte dos mesmos é canalizada para o Estado no financiamento de políticas públicas, contribuindo para a socialização dos custos de reprodução da força de trabalho. A política keynesiana, direcionada ao "pleno emprego" e à manutenção de um padrão salarial capaz de manter o poder de compra dos trabalhadores, implicou o reconhecimento do movimento sindical em sua luta por reivindicações políticas e econômicas. Permitiu, assim, que famílias pudessem aplicar sua renda monetária para consumir e dinamizar a economia. Ainda que não se possa falar de um Welfare State consolidado no Brasil, a prestação de serviços sociais públicos foi expandida, criando

\footnotetext{
Social de Manaus, agregada à universidade em 1962; 1945: Escola de Serviço Social de Niterói, que se incorpora à Universidade Federal Fluminense, em 1980; 1945: Escola de Serviço Social de Natal, agregada à Universidade Federal do Rio Grande do Norte, em 1969. Os dados referentes ao surgimento dessas escolas de Serviço Social no país se apoiam na pesquisa de doutorado de Larissa Dahmer Pereira (2007).
} 
condições para a constituição de um mercado profissional de trabalho e de institucionalização da profissão.

Condizente com a crescente influência dos Estados Unidos no cenário mundial no segundo pós-guerra, no contexto da Guerra Fria, o Serviço Social é receptivo à influência norte-americana, fundada na teoria sistêmica e no funcionalismo, expressa nas formulações do Serviço Social de caso, de grupo e no desenvolvimento de comunidade.

No período de 1965 a 1975 ocorre um marco importante no Serviço Social na América Latina: o movimento de reconceituação, impulsionado pela intensificação das lutas sociais no continente que se refratavam na universidade, nas Ciências Sociais, na Igreja, nos movimentos estudantis, com nítidas particularidades nacionais. Recusa a importação de teorias e métodos alheios à nossa história, na crítica aos fundamentos das abordagens de Serviço Social de caso, de grupo e de comunidade. De base teórica e metodológica eclética, esse movimento foi, inicialmente, polarizado pelas teorias desenvolvimentistas, e no início da década de 1970 ocorrem as primeiras aproximações do Serviço Social à tradição marxista, a partir de manuais de divulgação (Iamamoto, 2007, 2015, 2016).

O Centro Latino-Americano de Trabalho Social e a Associação Latino-Americana de Escolas de Serviço Social (Celats-Alaets) — hoje Alaeits desempenharam um papel exemplar na introdução do pensamento crítico no Serviço Social na América Latina vinculado aos interesses das classes subalternas, quando a pós-graduação e a pesquisa acadêmica davam seus primeiros passos nessa área. Contribuíram para o fortalecimento da organização acadêmico-profissional no marco continental, bem como para a construção da fraternidade dos povos latino-americanos no embate com as ditaduras militares e o imperialismo.

O período de vigência da reconceituação coincide com a vigência da ditadura militar no Brasil (1964-85), fazendo com que o nosso debate assumisse outras tonalidades e recebesse distintas influências, especialmente do vetor modernizador e tecnocrático, combinado com extratos da filosofia aristotélico-tomista no âmbito dos valores e princípios éticos, expresso nos Documentos de Araxá e de Teresópolis. Ou, nos termos de Aquin (2005), uma "reconceituação conservadora". 
Mas o país dispunha, nesse período, de um polo de resistência a essa vertente modernizadora, liderado pela Escola de Serviço Social da Universidade Católica de Minas Gerais (ESS/UCMG), integrado aos rumos do movimento de reconceituação latino-americano, tal como se expressou nos países de língua espanhola. É considerada por Netto (1991) como a formulação inicial e mais abrangente da vertente profissional no pós-1964, qualificada por ele de "intenção de ruptura" com as marcas conservadoras e modernizantes do Serviço Social brasileiro.

O Serviço Social brasileiro contemporâneo é expressão de amplo movimento de lutas pela democratização da sociedade e do Estado no país, com forte presença das lutas operárias que impulsionaram a crise da ditadura militar. Foi no contexto de ascensão dos movimentos das classes sociais, das lutas em torno da elaboração e aprovação da Carta Constitucional de 1988 e da defesa do estado de direito, que a categoria foi sendo socialmente questionada pela prática política de diferentes segmentos da sociedade civil e não ficou a reboque desses acontecimentos. O florescimento de um processo de lutas democráticas, cuja visibilidade no cenário político só se dá no último quartel da década de 1970, condiciona, fundamentalmente, o horizonte de preocupações emergentes no âmbito do Serviço Social com alterações nos campos do ensino, da pesquisa e da organização político-corporativa dos assistentes sociais. Revigora-se uma ampla e fecunda organização da categoria em suas bases sindicais, acadêmicas e profissionais.

No Brasil, a expansão monopolista provocou significativas alterações no processo produtivo, na reorganização do Estado, com irradiações no conjunto dos aparelhos de hegemonia da sociedade civil (em especial a universidade). Tais condições históricas tornaram possível a gestação de um novo perfil profissional ainda no período ditatorial: consolida-se um mercado de trabalho efetivamente nacional para os assistentes sociais, cresce o contingente profissional, realiza-se a efetiva inserção da formação nos quadros universitários e sujeita às exigências de ensino, pesquisa e extensão. E instala-se a pós-graduação stricto sensu, nutrindo a produção científica, o diálogo acadêmico com áreas afins, o mercado editorial e a renovação dos quadros docentes.

No período da crise da ditadura o Serviço Social vive um descompasso: ao mesmo tempo em que dispõe de condições materiais para dar o salto neces- 
sário visando responder ao avanço das lutas pelos direitos sociais e políticos, carecia de massa crítica para embasar uma autorrenovação nesses rumos. Dessa maneira, no universo do Serviço Social realizou-se um esforço de articulação entre a história do país, a crítica do conhecimento e a profissão, que passa a presidir o debate brasileiro no âmbito da tradição marxista (Iamamoto, 1992).

Durante o período ditatorial, muitos colegas foram capturados pelo ardil de transformar ciência em técnica social, subordinando-se à razão instrumental, seja pelo silêncio, seja pela conivência ativa com os poderes da ditadura. Buscavam o aperfeiçoamento técnico para a implementação de um conjunto de programas sociais compensatórios da repressão, do arrocho salarial e da desmobilização política das classes e grupos profissionais. Muitos se mostraram dóceis às orientações conservadoras e tecnocráticas a serviço do grande capital, ante a expansão do braço repressivo do Estado. Ali também foram sufocadas as primeiras iniciativas críticas que, durante o período desenvolvimentista, tiveram lugar nos trabalhos comunitários e de educação popular com apoio nas contribuições do educador brasileiro Paulo Freire.

Também houve lutas e resistências de parte de assistentes sociais, sendo uma de suas expressões a organização sindical da categoria (Abramides e Cabral, 1995). Muitos colegas foram vitimados pela repressão de Estado, sujeitos ao exílio ou à prisão arbitrária, tortura, condenados por tribunais militares guiados pela Lei de Segurança Nacional, expressão do terrorismo estatal. Essa história foi resgatada pelo CFESS nesses cinquenta anos da ditadura do Brasil.

\section{Desafios ao Serviço Social em tempos de crise}

No Brasil, o Serviço Social foi regulamentado como uma "profissão liberal", dela decorrendo os estatutos legais e éticos que prescrevem uma autonomia teórico-metodológica, técnica e ético-política à condução do exercício profissional. Entretanto, o exercício da profissão é tensionado pela compra e venda da força de trabalho especializada do assistente social, enquanto trabalhador assalariado, determinante fundamental na autonomia do profissional, impregnando essa atividade dos constrangimentos do trabalho alienado. Estabelece-se assim "a tensão entre projeto profissional e alienação do trabalho, indissociável 
do estatuto assalariado". Ou, em outros termos, repõe-se nas particulares condições do trabalho do assistente social profissional, o clássico dilema entre causalidade e teleologia, entre estrutura e ação do sujeito (Iamamoto, 2007).

A possibilidade de imprimir uma direção social ao exercício - moldando o seu conteúdo e o modo de operá-lo - decorre da relativa autonomia de que dispõe o assistente social, resguardada pela legislação profissional e passível de reclamação judicial. Essa autonomia é dependente da correlação das forças econômica, política e cultural em nível societário e se expressa, de forma particular, nos distintos espaços ocupacionais construídos na relação com sujeitos sociais determinados: no Estado (no Poder Executivo e Ministério Público, no Judiciário e no Legislativo); nas empresas capitalistas; nas organizações político-sindicais; nas organizações privadas não lucrativas e nas demais instâncias públicas de controle democrático (conselhos de políticas e de direitos, conferências, fóruns, ouvidorias). Tais espaços ocupacionais sofrem os impactos dos retrocessos políticos e econômicos para o conjunto dos trabalhadores.

Todavia, as atividades desenvolvidas sofrem outro vetor de demandas: as necessidades dos trabalhadores organizados, que, condicionadas pelas lutas sociais e pelas relações de poder, se transformam em demandas profissionais, reelaboradas sob a ótica dos empregadores.

A condição assalariada envolve, necessariamente, a incorporação de parâmetros institucionais e trabalhistas que regulam as relações de trabalho, estabelecendo as condições em que esse trabalho se realiza: intensidade, jornada, salário, controle do trabalho, indices de produtividade e metas a serem cumpridas. Os organismos empregadores redefinem funções e atribuições dos seus empregados; oferecem os recursos materiais, financeiros, humanos e técnicos indispensáveis à objetivação do trabalho; recortam as expressões da "questão social" que se tornam matéria da atividade profissional, o que condiciona conteúdo do trabalho realizado, estabelecendo limites e possibilidades à realização dos propósitos profissionais.

Essa ótica de análise requer articular a qualidade desse trabalho — sua diferencialidade dos demais tipos de trabalho - , expressa em seu caráter de atividade útil, que requer respostas técnicas e políticas de parte dos profissionais especializados, com sua identidade com o trabalho social médio, enquanto fração do trabalho social total (trabalho abstrato), que identifica o assistente social com 
o conjunto da classe trabalhadora, suas formas de organização e de lutas. Essas determinações são indissociáveis da mercantilização da força de trabalho.

Em um contexto recessivo, os assistentes sociais também sofrem a redução do trabalho formal, do acesso aos direitos trabalhistas e do salário indireto. Cresce o trabalho precário, temporário, a contratação por projetos, os quais geram insegurança na vida dos profissionais mediante a ausência de horizonte de largo prazo de emprego. A precarização das condições de trabalho atinge a qualidade dos serviços prestados e a relação com a população. Os crescentes índices de desemprego no país também incidem na categoria (Raichelis, 2011 e 2013).

Convivem hoje no mercado profissional de trabalho diferentes vínculos de ocupação: trabalho clandestino sem carteira assinada, contratação sem concurso público, atuação em cooperativas de prestação de serviços, terceirização e quarteirização de serviços em empresas já terceirizadas, ao lado de concursos públicos e vínculo empregatício protegido com direitos trabalhistas.

Além do baixo nível salarial e de sindicalização, temos ainda a inobservância da lei de trinta horas de trabalho de parte de muitos empregadores. Aliam-se situações de insalubridade e de assédio moral, como nos informa a Comissão de Fiscalização do Cress/RJ, a quem expressamos nossos agradecimentos (Cofi-Cress/RJ, 2014). É frequente a inobservância da Resolução do CFESS n. 483/2006, que dispõe sobre as condições técnicas e éticas para o exercício profissional do assistente social. Registra-se a carência de arquivos com chaves para a guarda de material sigiloso; as salas são inadequadas, com a presença de outras pessoas no ambiente de entrevistas reservadas que afetam o direito ao sigilo profissional do cidadão atendido pelo assistente social no que se refere à sua individualidade, o que deve ser respeitado no trabalho interdisciplinar. Constata-se em muitas das entidades empregadoras ausência de infraestrutura básica para a realização do trabalho profissional (telefone, computador, impressora, acesso à internet, carro para visitas domiciliares e intercâmbios interinstitucionais).

Ainda que a profissão e o ensino acadêmico-profissional tenham se secularizado ao longo dos anos, a religiosidade impregna a juventude estudantil na área, especialmente a de raiz protestante, que sobrepuja a influência católica 
das origens do Serviço Social. Atualmente o componente religioso é mais afinado com a ascensão social capitalista, expressando um trânsito da fraternidade à prosperidade. É importante reconhecer a liberdade de escolha religiosa, de foro privado, e respeitar o caráter laico do Estado na atuação profissional na esfera pública.

Verifica-se, simultaneamente, uma alteração na composição de classe do contingente profissional, reduzindo a distância social entre a categoria de assistentes sociais e o público atendido, com refrações no universo cultural dos estudantes. Por outro lado, a metamorfose na situação de classe dos estudantes cria uma ambientação favorável, apoiada na experiência de vida, à identificação com os dilemas do conjunto da classe.

Nesses espaços ocupacionais os(as) assistentes exercem suas competências e atribuições profissionais, resguardados(as) por lei: estudos socioeconômicos; orientação social a indivíduos, grupos e famílias; assessorias, consultorias e supervisão técnica; formulação, gestão e avaliação de políticas, programas e projetos; mobilização social e práticas educativas; instruções sociais de processos, sentenças e decisões; formulação do projeto de trabalho profissional e pesquisa; magistério, direção e supervisão acadêmica.

Deve-se ressaltar os esforços empreendidos sob a coordenação do CFESS para a qualificação das competências e atribuições do(a) assistente social nos segmentos mais representativos do mercado de trabalho: assistência, saúde, educação, área sociojurídica, previdência e, recentemente, junto aos migrantes (CFESS, 2010, 2012a, 2012b, 2013a, 2013b, 2014).

No trabalho cotidiano, o assistente social lida com situações singulares vividas por indivíduos e suas famílias, grupos e segmentos populacionais, que são atravessadas por determinações de classes. São desafiados a desentranhar, da vida dos sujeitos singulares que atendem, as dimensões universais e particulares, que aí se concretizam como condição de transitar suas necessidades sociais da esfera privada para a luta por direitos na cena pública, potenciando-a em fóruns e espaços coletivos.

Isso requer tanto competência teórico-metodológica para ler a realidade e atribuir visibilidade aos fios que integram o singular no coletivo quanto à incorporação da pesquisa e do conhecimento do modo de vida, de trabalho e 
expressões culturais desses sujeitos sociais, além da sensibilidade e vontade políticas que movem a ação. Estes são requisitos essenciais ao desempenho profissional. A cultura aqui compreendida como parte e expressão das forças políticas em luta pela hegemonia na sociedade nacional — o que requer decifrar as formas como a cultura dominante é interiorizada pelos dominados e as formas pelas quais é recusada, como nos lembra Chaui (1986, p. 24).

A política social é uma mediação fundamental do exercício profissional no âmbito das relações entre as classes e destas com o Estado no enfrentamento das múltiplas expressões da "questão social". O assistente social atua na formulação, gestão, avaliação e financiamento dessas políticas, assim como na assessoria aos movimentos sociais. Nas últimas décadas, consolidamos competências nesses âmbitos, e o espaço ocupacional ampliou-se, especialmente na seguridade social (saúde, assistência e previdência social em termos constitucionais) abrangendo o conjunto dos direitos sociais previstos no artigo $6^{\circ}$ da Constituição: educação, moradia, lazer, segurança e trabalho.

Só a política de assistência social absorve hoje mais de 40 mil assistentes sociais, presentes em todos os 5570 municípios do país. A atuação nos conselhos de políticas e de direitos - em especial aqueles de caráter deliberativo — tem sido um espaço privilegiado de controle social e democrático nas últimas décadas, contribuindo para a alocação mais democrática dos recursos públicos e para a ampliação da cobertura das políticas na perspectiva da universalidade do acesso. Entretanto, essa inserção tem ocorrido paralela a uma relativa secundarização da atuação junto aos movimentos sociais, organizações e luta das classes subalternas (Iamamoto, 2007; Simionatto, 1995; Abreu, 2002; Duriguetto, 2014; Duriguetto e Marro, 2016).

O Estado, nos diversos níveis da federação, é hoje o maior empregador dos assistentes sociais, e a atuação na órbita das políticas públicas é um espaço profissional privilegiado. Mas devemos recusar qualquer mimetismo entre política social e Serviço Social. Existe uma necessária autonomia entre o trabalho profissional na política pública e a política pública. Profissão não se confunde com política pública de governo ou de Estado e nem o Serviço Social se confunde com assistência social, ainda que esta possa ser uma das mediações persistentes da justificativa histórica da existência da profissão. Assim, seus 
agentes não são meros operacionalizadores de políticas emanadas do Estado - um braço operacional do moderno príncipe -, ainda que a política pública — e particularmente a seguridade social — seja uma mediação determinante no exercício da profissão no mercado de trabalho como uma das respostas institucionalizadas à "questão social". Certamente existem tensões entre projetos profissionais e políticas governamentais e nítidas disputas teóricas e políticas no direcionamento do Serviço Social brasileiro.

Assim, os assistentes sociais necessitam assegurar a elaboração de projetos de trabalho do Serviço Social nos espaços ocupacionais e atribuir visibilidade ao seu trabalho profissional no universo da politica social, afirmando suas competências/atribuições profissionais e "afinando" os seus instrumentos de trabalho (fichas, relatórios, pareceres, termos de visita, formulários e guias de entrevista etc.). E atribuir transparência às dimensões coletivas presentes nas demandas trazidas por indivíduos sociais nos atendimentos, nos plantões, nas entrevistas de seleção socioeconômica e em atividades grupais.

Neste sentido, é fundamental ultrapassar a leitura dos sujeitos com quem trabalhamos como "usuários de políticas" a qual obscurece seu pertencimento coletivo enquanto trabalhadores, como nos lembra Santana (2012; e apoiar a mobilização e a organização de segmentos da classe em defesa de seus direitos na cena pública, no processo de sua constituição política como classe.

Saliento a importância da retomada, do trabalho de educação política e de organização de base, numa conjuntura de hegemonia conservadora e de fragilização das esquerdas. Esta é uma direção que pode contrarrestar a tendência à judicialização dos direitos, em que prevalece a lógica do ganho individual e/ou financeiro, por meio de ações efetivadas no âmbito do Poder Judiciário.

$\mathrm{Na}$ formação acadêmico-profissional em Serviço Social, as universidades públicas e as PUCs congregam os cursos de excelência na área implementando as diretrizes curriculares propostas pela Abepss. Entretanto, predomina o ensino privado em instituições não universitárias, o que compromete a integração entre ensino, pesquisa e extensão. Isso ocorre em um contexto no qual o ensino superior passa a ser visto como "negócio educativo", e não como direito social.

Essas características são potenciadas pela expansão acelerada do ensino superior privado - particularmente no EAD —, com implicações na qualidade 
acadêmica da formação, no aligeiramento no trato da teoria, na ênfase no treinamento e menos na descoberta científica. A massificação e a perda de qualidade da formação universitária facilitam a submissão dos profissionais às demandas e "normas do mercado", tendentes a um processo de politização à direita da categoria.

Segundo o Censo Superior de 2009, o curso de Serviço Social já ocupava o terceiro lugar em número de matrículas na modalidade de EAD (CFESS, 2014, p. 24). A degradação da qualidade do ensino aí fartamente identificada é motivo de preocupação na defesa do legado ético-político construído pelo Serviço Social nas últimas décadas ante o ambiente de avanço do conservadorismo na sociedade. Ela pode ser ilustrada pelas condições do estágio curricular obrigatório e da supervisão acadêmica e profissional, atribuição privativa de assistentes sociais. Em levantamento efetuado em 2015 junto aos Cress (CFESS, 2014), a Comissão de Fiscalização do CFESS identificou situações que ferem a excelência do processo formativo: supervisor de campo com número excessivo de estagiários em relação à carga horária de trabalho; supervisor de campo sem vínculo trabalhista, atuando como voluntário; profissionais contratados exclusivamente para supervisão, com desconhecimento da dinâmica institucional; estágios sem supervisão direta de assistentes sociais. Na supervisão acadêmica são registradas situações como: excesso de estagiários, supervisão presencial esporádica, supervisão realizada à distância, acúmulo de papéis de supervisor acadêmico e de campo. Esta é uma questão que com certeza exige a atenção de todos.

\section{Conclusões}

Reunimos retalhos de nossa história e alguns desafios atuais. É hora de acumular forças no campo teórico e político e soldar a organização dos trabalhadores para fazer frente à vigorosa reação das forças regressistas. Como nos lembra Gramsci (1981, 1979, 2001), a criação de uma nova cultura - a filosofia da práxis - implica a elaboração de um pensamento superior ao senso comum, coerente, com bases científicas sólidas que, permanecendo em contato com os simples, encontra aí a fonte dos problemas a serem pesquisados e 
resolvidos. Ela apresenta-se como crítica do senso comum e da herança intelectual acumulada.

O momento histórico exige voltar a atenção para as lutas e movimentos dos trabalhadores enquanto classe - incluindo os assistentes sociais —, para a preservação e ampliação do trabalho, dos direitos conquistados e da crescente democratização das políticas públicas: a defesa da seguridade social na disputa pelo fundo público, do Sistema Único de Saúde, do Sistema de Único de Assistência Social, a luta contra a securitização da Previdência Social. E estar junto com os movimentos sociais e novos sujeitos coletivos na luta contra as desigualdades e disparidades sociais, na perspectiva de fortalecer a ação conjunta na defesa dos direitos sociais: os assalariados da indústria e dos serviços, os trabalhadores congregados na via campesina, os migrantes e deslocados (em especial bolivianos e haitianos no Brasil); a juventude organizada na defesa do ensino, do direito ao passe livre, em núcleos de cultura; as nações indígenas; os afrodescendentes, os grupos LGBT e as mulheres organizadas na defesa do trabalho e contra a violência doméstica, dentre outros.

Um caminho que pode ser fértil para acumular forças políticas e forjar a resistência é o retorno ao trabalho de base, ou seja, ao trabalho de educação política, apoiando seus processos de organização, capacitação e educação política, decifrando suas expressões socioculturais.

Faz-se necessário qualificar no exercício profissional a dupla dimensão presente no trabalho profissional, imprimindo-lhe plenitude de sentido: por um lado, a contribuição na reprodução material dos sujeitos, expressa na prestação de serviços sociais previstos nas políticas públicas; por outro, a dimensão educativa que incide na cultura das classes subalternas: nas suas maneiras de ver, viver e sentir a vida, que dispõem de uma dimensão coletiva na construção de uma contra-hegemonia, nos termos gramscianos. E, no que se refere ao projeto societário, estimular e apoiar uma frente de esquerda que crie um patamar mínimo de unidade para contribuir na construção coletiva de um projeto para o Brasil nesses tempos de regressão conservadora que historicamente tendem a ser acompanhados de crescente intolerância política.

Reafirmamos o compromisso com a defesa dos direitos, com a seguridade social pública, ampliada e universal. Recusamos a privatização da saúde, a 
securitização da Previdência Social e o desmonte do Suas: o retorno ao "primeiro-damismo" e a desprofissionalização da assistência social. Repudiamos a criminalização das classes trabalhadoras, de seus movimentos e das lutas populares. Todo apoio à organização e à formação política dos trabalhadores, respeitando sua autonomia de classe.

Com Milton Nascimento, expressamos nossas saudações às muitas Marias que fazem esta profissão predominantemente feminina, reafirmando com o conjunto de assistentes sociais brasileiros:

Mas é preciso ter força.

E preciso ter graça,

É preciso ter sonho sempre

Quem tem na pele esta marca

Possui a estranha mania

De ter fé na vida

Recebido em 26/9/2016 - Aprovado em 11/10/2016

\section{Referências bibliográficas}

ABEPSS/CEDEPSS. Proposta básica para o projeto de formação profissional. Serviço Social \& Sociedade, São Paulo, n. 50, p. 143-171, abr. 1996.

ABRAMIDES, M. B.; CABRAL, S. O novo sindicalismo e o Serviço Social. São Paulo: Cortez, 1995.

ABREU, M. Serviço Social e a organização da cultura: perfis pedagógicos da prática profissional. São Paulo: Cortez, 2002.

AQUIN, N. Reconceptualización: un trabajo social alternativo o una alternativa al trabajo social? Serviço Social \& Sociedade, São Paulo, n. 84, p. 48-65, 2005.

CFESS. Subsídios para a atuação de assistentes sociais na política de educação. Brasília: CFESS, 2010. (Trabalho e projeto profissional nas políticas sociais, n. 3.) 
CFESS. Atribuições privativas do/a assistente social em questão. $1^{\mathrm{a}} \mathrm{ed}$ ampl. Brasília: CFESS, 2012a.

. Política de educação permanente do conjunto do CFESS-Cress. Brasília: CFESS, 2012b.

. Parâmetros para atuação de assistentes sociais na política de assistência social. Brasília: CFESS, 2013a (reimpr.). (Trabalho e projeto profissional nas políticas sociais, n. 1.)

. Parâmetros para atuação de assistentes sociais na política de saúde. Brasília: CFESS, 2013 b (reimpr.). (Trabalho e projeto profissional nas políticas sociais, n. 2.)

. Sobre a incompatibilidade entre graduação à distância e Serviço Social. Brasília: CFESS, 2014. v. 2.

. CFESS Manifesta. Edição especial. Análise de conjuntura. Brasília, 7 jun. 2016.

CHAUI, M. Conformismo e resistência: aspectos da cultura popular no Brasil. São Paulo: Brasiliense, 1986.

CHESNAIS, F. Mundialização: o capital financeiro no comando. Outubro, São Paulo, n. 5, p. 7-28, 2001.

. As raízes da crise econômica mundial. Em Pauta, Rio de Janeiro, v. 11, n. 31, p. 21-37, 2013.

COFI-CRESS/RJ. Serviço Social e exercício profissional: principais questões postas pelo Cress $7^{\mathrm{a}}$ região. Trabalho apresentado no Enpess, 2014.

COUTINHO, C. N. Gramsci: um estudo sobre o seu pensamento político. Rio de Janeiro: Campus, 1989.

DURIGUETTO, M. L. Movimentos sociais e Serviço Social no Brasil, pós-anos 1990: desafios e perspectivas. In: ; ABRAMIDES M. B. Movimentos sociais e Serviço Social: uma relação necessária. São Paulo: Cortez, 2014. p. 177-194.

; MARRO, K. Serviço Social e movimentos sociais: atualidade de um legado histórico que alimenta os caminhos de ruptura com o conservadorismo. In: OLIVEIRA E SILVA, M. L. Serviço Social no Brasil: história de resistência e ruptura com o conservadorismo. São Paulo: Cortez, 2016. p. 97-118. 
FERNANDES, F. A revolução burguesa no Brasil: ensaio de interpretação sociológica. Rio de Janeiro: Zahar, 1976.

FURTADO, C. Um projeto para o Brasil. Rio de Janeiro: Civilização Brasileira, 1967.

GRAMSCI, A. Maquiável, a política e o Estado moderno. 3. ed. Rio de Janeiro: Civilização Brasileira, 1979.

. A concepção dialética da história. Rio de Janeiro: Paz e Terra, 1981.

. Cadernos do cárcere. Rio de Janeiro: Civilização Brasileira, 2001. v. 4.

HARVEY, D. O enigma do capital e as crises do capitalismo. Rio de Janeiro: Boitempo, 2011.

IAMAMOTO, M. V. Serviço Social na contemporaneidade. São Paulo: Cortez, 1992. . Trabalho e indivíduo social. São Paulo: Cortez, 2001.

. Serviço Social em tempo de capital fetiche. São Paulo: Cortez, 2007.

. A formação acadêmico-profissional do Serviço Social brasileiro. Serviço Social \& Sociedade, São Paulo, n. 120, p. 609-639, out./dez. 2014.

. Projeto de pesquisa. Movimento de reconceituação do Serviço Social na América Latina (Argentina, Brasil, Chile e Colômbia): determinantes históricos, interlocuções internacionais e memória. Brasília: CNPq, 2016.

. 50 anos do movimento de reconceituação. In: SEMINÁRIO LATINOAMERICANO DE ESCUELAS DE TRABAJO SOCIAL, 21., México, Mazatlán, set. 2015.

; CARVALHO, R. Relações sociais e Serviço Social no Brasil: um esboço de interpretação histórico-metodológica. São Paulo: Cortez, 1982.

MARX, K. Introdução. In: . Crítica da filosofia do direito de Hegel. São Paulo: Grijalbo, 1977. p. 1-14. (Temas de ciências humanas n. 2.)

MOTA, A. E. Serviço Social brasileiro; insurgência intelectual e legado político. In: OLIVEIRA E SILVA M. L. Serviço Social no Brasil: história de resistência e ruptura com o conservadorismo. São Paulo: Cortez, 2016. p. 165-182.

NETTO, J. P. Ditadura e Serviço Social. São Paulo: Cortez, 1991.

PEREIRA, L. D. Política educacional brasileira e Serviço Social: do confessionalismo ao empresariamento da formação profissional. Rio de Janeiro: UFRJ, Programa de Pós-Graduação em Serviço Social, 2007. 
PINHEIRO, Maria Isolina. Serviço Social: uma interpretação do pioneirismo do Rio de Janeiro. Documentário. Rio de Janeiro: Edições Uerj, 1985a.

. Serviço Social: infância e juventude desvalidas. Rio de Janeiro: Uerj/Cepuerj; São Paulo: Cortez, 1985b.

RAICHELIS, R. O assistente social como trabalhador assalariado. Desafios frente à violação de seus direitos. Serviço Social \& Sociedade, São Paulo, n. 107, p. 420-437, jul./set. 2011.

. Proteção social e trabalho do assistente social: tendências e disputas na conjuntura de crise mundial. Serviço Social \& Sociedade, São Paulo, n. 116, p. 609-635, out./dez. 2013.

SANTANA, R. O trabalho bruto no canavial. São Paulo: Cortez, 2012.

SIMIONATTO, I. Gramsci: sua teoria, incidência no Brasil e influência no Serviço Social. São Paulo: Cortez/UFSC, 1995.

VIOTTI DA COSTA, E. Da monarquia à República: momentos decisivos. São Paulo: Grijalbo, 1977.

YAZBEK, M. C. Estudo da evolução histórica da Escola de Serviço Social da PUC-SP no período de 1936 a 1945. São Paulo: Cadernos PUC, Educ/Cortez, 1980. v. 1, p. 11-60.

\section{Fontes eletrônicas:}

CAPES (Fundação Coordenação de Aperfeiçoamento do Ensino Superior). Disponível em: <https://sucupira.capes.gov.br/sucupira/public/consultas/coleta/programa/quantitativos/quantitativoAreaAvaliacao.jsf $>$. Acesso em: 25 maio 2016.

INTERNACIONAL FEDERATION OF SOCIAL WORKERS (IFSW). Disponível em: $<$ http://ifsw.org/membership/>. Acesso em: 25 ago. 2016.

MINISTÉRIO DE EDUCAÇÃO E CULTURA-SESU. Coordenação da Comissão de Especialistas de Ensino. Comissão de Especialistas de Ensino (CCEE). Comissão de Especialistas de Ensino em Serviço Social (Coness). Curso Serviço Social. Diretrizes curriculares. Brasília, fev. 1999. Disponível em: <http://www.cfess.org.br/arquivos/ legislacao_diretrizes.pdf>. Acesso em: 24 jul. 2014. 